\title{
PARQUES CIENTÍFICOS Y TECNOLÓGICOS: LOS NUEVOS ESPACIOS PRODUCTIVOS DEL FUTURO
}

\author{
Julio César Ondátegui \\ Universidad Complutense
}

\section{RESUMEN}

Los Parques Científicos y Tecnológicos (PCyT) están en constante evolución por todo el mundo. Este trabajo aborda el fenómeno desde sus orígenes hasta la actualidad. La primera parte platea los antecedentes (polos de los años sesenta) y la difusión de los proyectos tomando la referencia del modelo americano. En la segunda parte, dada la proliferación de iniciativas y situaciones reales, proponemos una definición que sirve para analizar el concepto mediante nuevos espacios productivos como el PT, la incubadora, el tecnopolo y la tecnópolis. Aunque parten de objetivos similares, la experiencia a escala internacional es diferente.

Estos espacios donde se localizan empresas de nuevas tecnologías están sirviendo tanto para rehabilitar y recualificar áreas urbanas como para atraer proyectos de nuevo contenido industrial. Como nuevas infraestructuras donde está concentrado el conocimiento y la tecnología, los PCyT serán efectivos tejiendo redes, estableciendo flujos con el tejido industrial, así como creando industrias y no sólo empresas.

Palabras clave: Planificación, Parques Científicos y Tecnológicos, Innovación, Tejido Industrial.

\begin{abstract}
The Scientific and Technological Parks are all over the world in constant evolution. This paper approaches the phenomenon from its origins until the present time. The first part thinks about the antecedents (poles of the sixties) and the diffusion of the plans taking like reference the american pattern. In the second part, given the proliferation of initiatives and real situations, we propose a definition that is good to analyze the concept through new productive spaces as the PT, the incubator, the tecnopolo and the tecnópolis. Although they leave of similar objectives, the experience to international scale is different.

These spaces where companies of new technologies are located are being good so much to restore and recover urban areas as to attract projects again industrial content. As new infrastructures where it is concentrated the knowledge and the technology, the PCyT will be effective knitting nets, settling up-down flows with the industrial fabric, as well as making industries and not only companies.
\end{abstract}

Key words: Planning, Scientific and Technological Parks, Innovation, Industrial Fabric. 


\section{El fenómeno de los PCyT: antecedentes y evolución}

Cuando se investiga el significado y los objetivos de lo que hoy en día se conoce con el genérico de parques científicos y tecnológicos, éstos como todo fenómeno nuevo relacionado con la industria y el territorio han dado lugar a una serie de controversias entre expertos, políticos, planificadores y demás estudiosos del tema. Por un lado, como plantean MÉNDEZ-CARAVACA (1995), se trata de una de las propuestas con mayor profusión que los agentes públicos están utilizando para el desarrollo de la industria de nuevas tecnologías como medida para reactivar los sistemas industriales y lograr una posición competitiva de las economías urbanas y regionales. De otra parte, el hecho de transplantar un modelo más o menos espontáneo a contextos diferentes dificulta la aplicación del modelo.

\subsection{El origen de los parques: entre polos y tecnopolos}

Cuando se rastrea la realidad del desarrollo regional no muy lejano y la bibliografía, uno se encuentra con el «polo industrial» de los años 1950, 1960 e incluso en la década de los setenta en España, cuando el crecimiento económico se planificó con los polos de desarrollo de F. Perroux, quien en 1955 planteó por primera vez este concepto.

«Constituye un polo de crecimiento, una industria que condiciona el desarrollo y el crecimiento de industrias en relación técnica con ella —polarización técnica-, a causa de los productos que es susceptible de originar, determinando la prosperidad del sector terciario por la vía de los ingresos que origina —polarización de los ingresos-o un incremento de la renta regional, provocando una concentración progresiva de nuevas actividades en un lugar dado, por la perspectiva de poder disponer de ciertos factores o facilidades de producción — polarización psicológica o geográfica-»1.

Mediante este concepto teórico se descentralizó la industria con el fin de crear una polarización económica, técnica y de empleo que elevara el nivel de vida en áreas próximas a las grandes ciudades. El sentido primero del término indica una ciudad de la técnica, es decir, ciudad o centro industrial marcado por las actividades industriales. Pero tras el periodo de crecimiento, el contexto económico cambia, el desarrollo polarizado dirigido por el Estado toca a su fin y el protagonismo se deriva hacia las regiones y ciudades quienes adquieren mayor poder en la planificación. Esto mismo, junto al cambio de paradigma industrial y la importancia que adquieren las nuevas tecnologías, han permitido una evolución hacia los tecnopolos actuales.

El término tecnopolo aparece regularmente en la literatura a finales de los años 1970 . Los proyectos de tecnopolos actuales reposan sobre el concepto de fertilización cruzada, descrito por P. Laffitte fundador de Sophía-Antípolis como «la reunión en un mismo lugar de actividades de alta tecnología, centros de investigación, empresas, universidades, así como organismos financieros que, facilitando los contactos entre estos agentes, produce un efecto de sinergia de donde pueden surgir las ideas nuevas, las innovaciones técnicas y suscitar la creación de empresas» (DATAR, 1988).

1 Aydalot, Ph., (1965). «Notes sur les économies externes et quelques notions connexes», en Revue Económique, nov. 1965, pp. 944-973. París. Citado en Prados, J., (1972). Estudios de economía política. pp. 182 y 183, Ed. Guadiana, Madrid. 
Inicialmente son un agrupamiento de organizaciones de centros de investigación y de empresas que buscan el desarrollo científico desde la etapa de laboratorio hasta la comercialización de los productos. En Francia son iniciativas puestas en escena por ciudades, donde la estrategia de desarrollo económico se apoya en el aprovechamiento del potencial universitario y de investigación con la esperanza de abrir iniciativas de industrialización nuevas mediante empresas de alta tecnología.

Sin embargo, el concepto pronto se amplía a una operación mixta de actividades económicas, zonas residenciales y equipamientos, en donde la simple atracción de empresas es considerada como uno de los objetivos y funciones para la innovación desde estos nuevos espacios. Así, los proyectos contenían toda una estrategia de promoción económica, industrial, inmobiliaria e incluso social, en los que «los políticos locales ansiosos de sí mismos y de la prosperidad de sus electores, están particularmente interesados por la implantación de un espacio de calidad, que localice empresas y cree empleos cualificados» (BENKO, G., 1991, 14).

La descentralización del desarrollo urbano en la región de París durante los años setenta, el posterior crecimiento de los años ochenta y los intentos de una política para crear nuevas ciudades satélites, aceleraron la creación de tecnopolos. La decisión de crear estos espacios innovadores no surge tanto de una política nacional de desarrollo como de una iniciativa regional o local. Así, toda colectividad territorial, pero también todo organismo público o privado, puede crear tecnopolos o parques tecnológicos, lo que explica la diversidad de términos y actuaciones tanto en Francia como actualmente en Italia, en España y en general en el mediterráneo occidental.

El resultado de esta evolución y su significado para los parques ha sido un desarrollo dirigido por las autoridades regionales. El mismo Benko equiparó los tecnopolos a los parques tecnológicos, poniendo como ejemplo clásico en su estudio Sophía-Antípolis. Y, Castells también analizó como ejemplo de parque tecnológico incluido en su tipología el mismo proyecto urbano que Benko. Por tanto, ya tenemos tecnopolo equiparado a parque tecnológico (PT) como medio de innovación o espacio para la innovación, aunque todavía no a tecnópolis, por lo menos en España, pese a los esfuerzos por incorporar el término en proyectos urbanos.

\subsection{El precursor de los PCyT actuales: ¿planificación o espontaneidad?}

Dentro de las diferentes dinámicas metropolitanas y tecnopolitanas, uno de los instrumentos con el que se ha trabajado para concentrar, desarrollar y difundir tecnología a partir de conocimientos y, por tanto, potenciar los procesos de innovación mediante sinergias entre instituciones científicas y las necesidades de los sectores productivos, ha sido la creación de parques científicos y tecnológicos. Primero en los EE.UU, después en Europa y posteriormente en el sudeste asiático. En estos espacios productivos es donde se crean nuevas estructuras científicas y socioeconómicas apoyadas en el conocimiento, en las ideas y en la cooperación entre los entornos institucional, académico y productivo.

El antecedente inmediato de los parques científicos y tecnológicos está estrechamente ligado a la experiencia del Silicon Valley. Allí, y durante varias décadas, la colaboración entre empresas, organizaciones militares, universidades, departamentos del gobierno norteamericano y entidades financieras de capital riesgo, fueron los agentes imprescindibles para crear un tejido empresarial, social e investigador que posibilitó un rápido avance tecnocientífico. 
Una serie de avances tecnológicos y científicos convergentes surgidos décadas atrás, cristalizaron por los años setenta en Estados Unidos en grandes innovaciones tecnológicas en los sectores de la electrónica, informática, ordenadores y satélites espaciales. En estas actividades las nuevas empresas creadas y otras ya existentes reorientadas se localizaron en nuevos espacios industriales denominados en principio parques tecnológicos.

Fueron tan innovadores que los parques posiblemente no existirían sin la universidad de Stanford, que con sus graduados favoreció la implantación de empresas en su campus. Además, estas empresas que generaron nuevas empresas a partir de procesos de escisión de sus plantillas, fueron apoyadas por un mercado de capitales que facilitó la innovación y el desarrollo empresarial. Así y allí surgió el embrión de las tecnologías de la información y de las telecomunicaciones, que difundidas por el mundo han dado lugar a la aparición de las grandes empresas multinacionales del sector telemático.

Un segundo grupo de elementos definitorios bien significativos de los parques tecnológicos, es la importancia que frente a la lógica del mercado se atribuye a las instituciones públicas en el proceso de gestación. El Estado directamente, y los gobiernos autónomos e instituciones públicas y semipúblicas, han sido decisivos para crear los nuevos parques en los últimos quince años. Sin ellos, y sin los centros de investigación y las universidades en estrecha conexión con el tejido empresarial, las sinergias requeridas para iniciar el desarrollo son escasas o nulas y a veces difíciles de conseguir. Esto mismo según Castells puede conllevar al fracaso de los proyectos sobre todo en países y regiones semiperifericos con mayor debilidad de su estructura empresarial.

Es decir, que en la orientación del nuevo desarrollo tecnológico si bien es cierto que entre los centros de investigación se incluyen aquellos pertenecientes a grandes empresas tecnológicamente avanzadas o aquellos otros especializados en líneas de investigación, sin una planificación que incluya aspectos sociales, culturales, económicos, etc., y sin una estrategia de apoyo y estímulo al tejido industrial, lo cual sólo es posible desde los poderes públicos, no se asegura el desarrollo tecnológico endógeno y competitivo.

En este sentido, los estudios de los parques coinciden en varios aspectos relacionados con los agentes impulsores. Ahora bien, conviene hacer una precisión sobre los acontecimientos causales de lo que se considera el germen de los primeros espacios innovadores, a partir de la cual se establecen diferencias iniciales. Tanto el Silicon Valley como el área de Boston, guardan estrecha relación con la reindustrialización, el cambio tecnológico en la industria de guerra y ciertas instituciones como la universidad de Stanford y el MIT. Los acontecimientos que subyacen en el desarrollo de los complejos de alta tecnología en los EE.UU, incluido el área de Boston donde existía cierta tradición empresarial y la industria cambia hacia una economía de «alta tecnología» y servicios avanzados, se han resumido como sigue:

— El eje de la investigación avanzada en electrónica fueron el MIT y la universidad de Harvard en menor medida.

- El Departamento de Defensa prestó los fondos y sobre todo los pedidos de bienes equipos y servicios industriales.

- Los conocimientos avanzados y los contactos con el ejército para crear empresas se aportaron a través de los docentes de la universidad y los graduados del MIT.

- La falta de competencia mundial durante los años 1940 y 1950 en la tecnología electrónica provocó la escisión de empresas dando nacimiento a los complejos y a las economías de escala favorecidas por una mano de obra de alta calidad fruto de la 
buena formación y de la tradición industrial (SAXENIAN, A., 1990; CASTELLS, M.; HALL, P., 1994).

A partir de este esquema, en los años ochenta y noventa se han visto Silicon Valleys en Europa (el fenómeno Cambridge, la concentración de industria electrónica en Escocia, Grenoble en Francia, o la new town de Tres Cantos en España). Sin embargo, ¿cuánto han cambiado las condiciones mundiales de competencia? ¿Qué industrias militares en Europa o en España están en condiciones de realizar el arrastre? ¿Se puede repetir esta cadena de factores en otros territorios o regiones? ¿Son imitables los complejos de alta tecnología o los parques tecnológicos derivados de ellos? El mismo Castells dice que no es posible imitar experiencias como la del Silicon Valley, porque «la propia existencia del Silicon Valley ha cambiado para siempre la división del trabajo en la investigación y producción de alta tecnología impidiendo, irónicamente, la imitación directa de su propia existencia» (CASTELLS-HALL, 1994, 57).

El movimiento de parques tecnológicos comenzó entre 1947 y 1948 cuando se inventaba el transistor, cuando en Europa se entraba en la economía de los años cincuenta y cuando se iniciaban planes de desarrollo aplicando la teoría de los polos de Perroux. Ésta es la diferencia temporal, espacial, económica y social. La experiencia iniciada en los EE.UU. tiene su equivalente en Europa con el «polo de desarrollo», y el tecnopolo nos conduce a los parques tecnológicos, pero éstos vistos con cierta perspectiva tienen su origen en un fenómeno en el que de la espontaneidad inicial se ha pasado a la planificación estratégica y ejecutiva del modelo.

Aquéllas condiciones que caracterizaron el potencial que representaban los descubrimientos científicos de mediados de siglo canalizadas a través de los mecanismos directos del mercado, varias décadas después cambian y la acción de las instituciones públicas condicionantes del desarrollo económico van a ser el motor principal de los nuevos espacios de innovación. Una serie de factores comunes necesarios para el nacimiento de PCyT a partir de las características técnicas urbanas y, sobre todo, de las decisiones adoptadas por los agentes para atraer, localizar y crear empresas de alta tecnología en Europa, las han observado BENKO, G. (1991) al analizar los tecnopolos franceses y MALEZIEUX, J. (1993) en la aglomeración parisina ${ }^{2}$. Así, la función que juegan las universidades y los institutos de investigación se considera fundamental. Los poderes públicos con una oferta y acceso a servicios de formación, información y de capitales, favorecen la implantación de industrias de alta tecnología. El medio ambiente agradable, las infraestructuras de transporte y comunicaciones, la flexibilidad en materia de recursos humanos y sus cualificaciones, son sólo factores coadyuvantes. Y, las economías de aglomeración junto a las políticas de descentralización, configuran un último bloque de factores externos a empresas para configurar los nuevos espacios productivos.

\subsection{Difusión del fenómeno PCyT}

Los parques fueron conocidos fuera de los valles californianos hasta el punto que en todo el mundo se ha querido reproducir el fenómeno pero, como los procesos fueron de tipo

2 A partir de la experiencia francesa, la política de desarrollo territorial implementada por las administraciones habría dado lugar a los centros de innovación, los parques científicos, los tecnopolos o parques tecnológicos, los parques comerciales y de negocios, y las zonas industriales superiores. Véase Benko, G., (1991). pp. 13-19, obra citada. 
múltiple y específicos de un lugar, la adaptación del fenómeno a las distintas regiones se ha producido de forma parcial. La experiencia del Silicon Valley en sus distintas manifestaciones ha dado lugar a la planificación de PCyT. Países, regiones, municipios, universidades, fundaciones y empresarios han intentado copiar los procesos que allí se produjeron. Existen experiencias a escala mundial del fenómeno con diferentes resultados.

1. Estados Unidos. El origen del término se remonta a la creación del parque industrial de Stanford. El parque fue ideado por el visionario decano de ingeniería eléctrica Frederick Terman, y las escisiones de la empresa fundada por uno de los inventores del transistor en 1948 (Shockley), quienes tras formar parte del cuerpo docente de Stanford, proporcionaron el impulso a partir del cual se desarrolló el Silicon Valley. Este fenómeno, que surgió en Palo Alto, en el valle de Santa Clara (California), resucitó la vitalidad del valle a lo largo del tiempo. Según SAXENIAN $(1990,1991)$, se creaba una nueva empresa cada dos semanas durante los años setenta. Seguidamente, las redes sociales de información entre los directivos, empresarios e ingenieros, entraron en una competencia directa por el negocio de la innovación tecnológica. Estas sinergias continuaron escindiendo y segregando a otros grupos sociales y a otras actividades económicas creando múltiples parques industriales en el área geográfica inmediata: Mountain View, Sunnyvale, San José, Cupertino.

Así nació este complejo industrial, mediante una concentración de conocimientos en un país capaz de mitificar un área geográfica con la tecnología. Los parques estadounidenses están ligados a sectores tecnológicos emergentes que aprovechan la capacidad científica e innovadora de la universidad a la que están asociados, atraen nuevas inversiones y empresas «high tech» convirtiéndose de manera espontánea en importantes instrumentos de desarrollo regional. Otro elemento interesante del modelo norteamericano es la vocación de autofinanciación de los parques, a veces incluso proporcionando beneficios a sus promotores, para ello parten normalmente de un planteamiento empresarial, lo que excluye habitualmente el que acaben dependiendo de fondos públicos como ocurre en otros países.

En EE.UU., la mayor concentración de empresas de alta tecnología está dentro o cerca de un parque científico, y, en cualquier caso, próximas a universidades o centros de investigación. A los clásicos ejemplos del Silicon Valley en el área de San Francisco o la Ruta 128 en Boston (Saxenian, A., 1990, 1993, 1994), se han sumado diversas áreas innovadoras de excelencia como son: Seatle donde se concentran actividades de bioquímica y software, la industria de semiconductores en Mineapolis-St Paul, Philadelfia y Tucson, los parques científicos de Triangle Park 1 U, North Carolina, Duke U., Massachusetts-1 28/MIT-Harvard U.-Brandeis U-Boston U., y otros parques como Torrey Pines-San; Diego 1; UCSD-SDST-Scripps Institute-Salk Institute. Una nueva corriente que emerge es la aparición de parques especializados en actividades biomédicas, telecomunicaciones, desarrollo de software, etc., como el Biomedical Research and Development Park, o el de la Universidad de Columbia.

Finalmente, destacar la enorme importancia que prestan en la creación de «start ups» (empresas de nueva creación) y «spin offs» (nuevas empresas resultado de una actividad realizada en un centro universitario o en otra empresa). Los estados que pueden considerarse líderes por la importancia que en ellos tienen los parques, atendiendo al número de personas que emplean son California y Carolina del Norte con cerca de 60.000 cada uno, Nueva York con unos 27.000 y Alabama con 25.000 empleos.

2. En Europa, aunque los gobiernos desempeñan un papel fundamental, en todos los países no nacen de la misma manera. La creación de parques científicos en el norte de Europa ha sido y es una de las vías importantes que la universidad eligió para rentabili- 
zar el conocimiento, y para dar soporte al desarrollo de la sociedad de la información. Además de centros o ciudades innovadoras tradicionales donde se concentran funciones políticas, productivas y tecnológicas como Londres, la Ciudad Científica de París o el área de Munich en Baviera, podemos añadir ciudades medias especializadas en la industria aeronáutica como es el caso de Toulouse y algunos ejemplos pioneros como el Cambridge Scientific Park. La rápida proliferación de los PCyT se da en la década de los años ochenta por iniciativa de las universidades, con el objetivo de transformar sus conocimientos científicos y tecnológicos en riqueza económica. Concretamente es en el norte de Europa, en Escocia, Holanda, Inglaterra y Suecia. Curiosamente, en uno de ellos, el Roslin Institutde Edinburg Technopole, es donde ha nacido Dolly la primera oveja clónica.

En cuanto a la estructura y financiación, estos parques se encuentran normalmente estructurados en forma de sociedades limitadas o anónimas, o bien como fundaciones. En los consejos rectores de los parques o de otras sociedades asociadas a ellos se encuentran representadas las universidades, las administraciones locales y regionales, las empresas, y los bancos y entidades financieras. Por ejemplo el ldeon Center AB está participando por la Universidad de Lund (Suecia) en un 20\%, por otros capitales públicos en un $10 \%$, y por capital privado en un $70 \%$. La primera empresa privada que invirtió capital fue IKEA.

La creación de estos espacios generalmente tiene una repercusión directa sobre el territorio donde se ubican, ayudando a revitalizar las ciudades ya se encuentren en una etapa de estabilidad económica o bien con problemas económicos puntuales. Así surgió, a mediados de los años setenta, el ldeon Center AB asociado a la Universidad de Lund como alternativa a la crisis económica de las atarazanas del sur de Suecia, que no podían hacer frente a la competencia de las empresas japonesas y coreanas.

También el Zernike Science Park, asociado a la Universidad de Groningen (Holanda) creado con la intención de reducir la tasa de paro de la ciudad, que estaba en un 23\%, el $40 \%$ de la cual correspondía a titulados universitarios. Al cabo de siete años de funcionamiento del parque se han creado 3.000 puestos de trabajo directos, la mayoría cubiertos con titulados universitarios. En el Zernike Science Park se ha constituido una compañía limitada, la Zernike Seed Fund BV (ZSF), con la finalidad de financiar las empresas del parque. Esta compañía está participada por la Universidad de Groningen, el banco ABN AMRO, la compañía de seguros AEGON, una compañía para el desarrollo, NV NOM, y una compañía privada, la Zernike Group. La Zernike Seed Fund BV (ZSF) invierte elevadas sumas en cada empresa. En los últimos años se han estudiado 800 proyectos que han representado la formación de 100 empresas. Una experiencia diferente, es la del Novum Research Park a Huddinge, al sur de Estocolmo. Este parque fue creado a finales de los años ochenta para potenciar científicamente la parte sur de esta ciudad sueca y así poder crear una nueva universidad.

Finalmente, en otros casos, una entidad bancaria participa en la iniciativa de desarrollo del parque, como es el caso de la University of Warwick Science Park, cercana a la ciudad de Birmingham, con estructura de sociedad limitada, promovida por la Universidad de Warwick, el Consejo de la ciudad de Coventry, la junta de empresas de West Midiands y el Consejo del Condado de Warwickshire. Aquí, la participación del Barclays Bank fue fundamental para la construcción de los primeros edificios. Además, este banco, Coopers \& Lybrand, y el equipo director del Parque han creado un grupo de trabajo con el objetivo de asesorar a las empresas que quieren entrar en el Parque y realizar un seguimiento de las ya existentes. 
El Reino Unido siguiendo el ejemplo americano desarrolla sus parques tecnológicos tomando la universidad como motor. El Corredor M-4 o Creciente Occidental comenzaba a ser operativo en la década de 1960. Los parques de ciencia como Herriot Watt Science en Edimburgo y Cambridge Science Park son los primeros ejemplos de éxito que acuñan el término de parques científicos en los años setenta. Cambridge data de los años 1970, y fue una iniciativa semiespontánea debida a escisiones de la universidad con un desarrollo de tipo productivo inicialmente lento. Posteriormente, debido a la escasa participación de la iniciativa privada, el escaso empleo generado y los débiles resultados (MASSEY, D. y otros, 1991), comienza una segunda oleada de parques que dan prioridad a la creación de empresas innovadoras en incubadoras movilizando capital riesgo.

Este entorno económico por el que la participación de empresas del sector privado en la administración de los parques, en muchas ocasiones, asegura un buen funcionamiento y los parques se convierten en una garantía para algunas empresas. Estudios recientes de la IASP $(1997,1999)$ en los parques han demostrado que las empresas de capital riesgo tienen mayor tendencia a invertir en empresas instaladas en un parque. La razón de esto es que las empresas instaladas en parques han superarado el estudio del consejo de administración que, en base a la viabilidad económica y la innovación tecnológica, da la luz verde al proyecto. Además, los parques ejercen sobre las empresas una función de tutela que hace que la cota de éxito sea superior a la de empresas no localizadas en parques. En el Zernike Science Park, de las 63 empresas creadas en los últimos siete años, solamente se han dado dos abandonos.

En Francia son agencias públicas y centros regionales de investigación, quienes siembran las regiones y las ciudades de espacios para la innovación y tecnopolos, intentando reducir las desventajas respecto a los principales polos de investigación científica y tecnológica tradicionales concentrados en la región Ille de France. Utilizando la tecnología y sus propios recursos con el objetivo de «ponerlos en valor», se definen los modelos de tecnópolis o tecnopolos y, como en Japón, son las ciudades y los ayuntamientos los que asumen el protagonismo para crear «polos de excelencia». El fenómeno francés persigue el crecimiento de pequeñas ciudades medianas en áreas no metropolitanas con el crecimiento de nuevas funciones de tipo avanzado. Este es el caso de las ciudades del sur de Francia, y en particular el mayor activismo local de Lyon, o Grenoble, e incluso en la misma franja están Montpellier, Tolouse y la ciudad nueva de Sophía Antípolis.

A partir de experiencias como Zirst de Meylan-Grenoble y Sophía Antípolis en la Costa Azul, cuyo impulso inicial corresponde a una escuela pública con el activismo de las autoridades locales y la ayuda posterior del gobierno central y de empresas nacionales, surgieron los tecnopolos que, en general, ya no se limitan a gestionar una única área donde se concentran las actividades de alta tecnología sino que, coordinan varias zonas de una misma ciudad (Burdeos, Toulouse, Rennes, Montpellier). Montpellier-Europole, por ejemplo, integra cinco polos especializados: Euromédicine ligado a la sanidad, Agropolis especializado en los recursos de la tierra, Anntena en multimedia, Communicatique en informática y robótica, y, finalmente, Heliopolis en turismo y actividades recreativas. En el modelo francés que persigue ciudades de técnicos y cuadros, se ha intentado descentralizar actividades avanzadas de alta tecnología apoyadas en empresas y centros de investigación públicos, con una composición de la población que va adquiriendo un panorama social y profesional mixto (PERULLI, P., 1995).

En Alemania, ocupan un lugar preferente los Centros de Transferencia de Tecnología. Además de los CEIs, como política de innovación establecida a principios de 1980 destaca 
el BIC de Berlín del que surgen varios parques tecnológicos. Estructuras directamente vinculadas al gobierno han convertido al land de Baden-Württemberg con más de cien centros en el mayor polo de transferencia tecnológica interna en Alemania. En las experiencias con buenos resultados predomina una interacción entre Centros Tecnológicos y Parques Tecnológicos (ADEN, W., 1994; ALLESCH, J., 1995).

Italia es un territorio sembrado de iniciativas para impulsar la innovación y el desarrollo tecnológico mediante PCyT. El gobierno italiano a finales de los años ochenta inició un programa para reproducir la iniciativa de Bari financiada por la Cassa del Mezzogiorno. Actualmente existen iniciativas en curso como el entorno innovador Tecnocity en el triángulo Turín-Ivrea-Novara, el polo tecnológico Bicocca en Milán, Leonardia en Picenza, etc. (figura 1).

Los proyectos para propiciar la innovación en la Península alpina se localizan en Trieste, en la tecnópolis de Valenzano-Bari y, mediante los Consorcios de Ricerche, actualmente se desarrollan el parque tecnológico de Pisa y el de Génova. Y, ya en los años noventa aparecieron políticas específicas con un programa tecnopolitano de 1,5 billones de liras para el sur con una docena de proyectos, hasta el punto que cada región del sur contará con un parque, excepto Campania y Apulia que tienen planificados dos.

Uno de los parques más antiguos es Tecnópolis Novus Ortus, en Bari, que concentra potentes centros de investigación propios y de grandes empresas en un espacio muy reducido. En 1994 contaba con 230 empleos propios, en su mayoría investigadores, lo que puede ser un hecho atípico pues este personal incluidos técnicos no suelen pasar del $40 \%$ ó 50\%. Este parque marca tendencias diferentes: por un lado, el personal de gestión tiende a reducirse al mínimo y, por otro, porque los nuevos proyectos del sur deberán producir resultados útiles a la industria y en general a la economía local en la medida que no está previsto financiar investigación básica.

Dentro de la Península Ibérica, en España son los gobiernos regionales (ONDATEGUI, J. 1997, 1999, 2000), y en Portugal fundamentalmente es el Estado quienes están desarrollando los parques científicos y tecnológicos. Portugal tiene planificados proyectos en Coimbra a partir de la evolución las actividades de innovación que realizan una docena de empresas localizadas en la incubadora de Empresas del Instituto Pedro Nunes. En el área de Lisboa se localiza el parque de ciencia y tecnología (TAGUSPARK) y, en principio, en los mismos términos pero con un carácter más inmobiliario, el de Oporto con tres polos localizados en Feira, Maia, e Vale do Ave, con unos 400 empleos previstos en 1997 dispuestos a competir con Lisboa (GAMA, R., 1997; VEIGA, 1997).

3. Asia. Al margen de la emergencia de un sector orientado a la tecnología en la India y de las planificadas nuevas áreas industriales en la extensa costa de China, nuevas ciudades asiáticas que habían adquirido funciones centrales de producción en los años ochenta, ahora están concentrando además de las tareas de ensamblaje estandarizadas, actividades de producción avanzada con mayor cualificación.

El tan conocido como desconocido archipiélago japonés contaba en los años ochenta con veinte ciudades definidas en donde se localizaban experiencias de parques científicos y tecnológicos. Actualmente, con una planificación sensiblemente diferente al modelo europeo se fomentan e impulsan iniciativas similares en 30 ciudades (ABE, S., 1998; EDGINGTON, D., 1999).

La industria se descentraliza desde las megalópolis localizadas en el Pacífico hacia las ciudades del interior y de la costa oeste (FUYITA, M.-ISHII, R., 1999). Pero además un paso tal vez significativo de esa mezcla de símbolos que plantea Castells en su trilogía 
sobre la sociedad de la información, es que a los clásicos factores y elementos diseñados para planificar las ciudades de la ciencia y la tecnología de los años ochenta, se suma el activismo de la población expresando los sueños y sugiriendo el modelo de ciudad y sus contenidos al que aspiran mediante redes telemáticas fácilmente accesibles, oficinas de la administración y reuniones de grupos en las que de la visión se pasa al cultivo y a la realización. Esencialmente este proyecto de «softtopía» parte de una cierta desmaterialización y supone la participación de todos los ciudadanos en la discusión y en las actividades para crear un ambiente satisfactorio y agradable (GIFU, 1998).

Desde 1992 estas «fábricas de información para el mañana» iniciadas en la tecnópolis de Gifu localizada en el interior de la isla principal se han extendido por media docena de prefecturas. Las ciudades medias y pequeñas están modificando la planificación y la base económica mediante la combinación de servicios e industria nueva ligada a la agrobiología, pequeñas unidades de I+D en productos alimenticios, textil, moda, papel y electrónica.

En Singapur, como en Japón, el microprocesador se aplica en las carreteras, aeropuertos, ingeniería civil y vigilancia de presos. Este pequeño territorio con una población que dobla al censo de las Islas Canarias es una verdadera tecnópolis por las rápidas soluciones que suceden a las necesidades de la población. La reproducción del Silicon Valley en Singapur se apoya en la confluencia de redes de empresas de alta tecnología como Conner Peripherals, Hewelet Packard y Thomson-SGS, que descentralizaron actividades a finales de los años ochenta.

Durante los años noventa destaca por su industria de alta tecnología (reparación de aviones, equipos electrónicos y servicios avanzados) que constituyen el 75\% del PIB y del sector servicios. Su puerto con excelentes instalaciones para el tráfico de contenedores, reexporta productos refinados del petróleo para los países del área y bienes de equipo para todo el mundo. Este país es todo un parque tecnológico. Desde 1998 el gobierno trabaja en un plan para crear una ciudad futurista mediante el programa Singapore One: un «superpasillo multimedia» que conecta a los hogares, escuelas y empresas mediante la oferta de servicios. En este proyecto se invierten 60.000 millones de pesetas al año para vincular toda la población en el año 2002 con tecnología avanzada.

En Taiwan, el parque tecnológico de Hsin-Chu es uno de los principales focos proveedores de equipos y componentes electrónicos e informáticos del mundo. En este silicon taiwanés que a finales de 1999 daba empleo a más de 60.000 personas se concentran la alta tecnología del pequeño país asiático. En él están localizados centros tecnológicos públicos y plantas de empresas como Taiwan Semiconductor Manufacturing especializada en memorias DRAM con tecnología de 0,15 a 0,25 micras, Acer uno de los mayores productores de ordenadores del mundo, United Microelectrónica Group con seis fábricas de microprocesadores en el parque, y la compañía Microtek Intenacional, especializada en equipos electrónicos para impresión con una cota del $12 \%$ en el mercado mundial en escáneres.

4. Otras áreas geográficas. El fenómeno se ha extendido por Israel y África donde en el año 2000 hay una docena de proyectos en marcha. En América del Sur el concepto de parque surge a finales de los años 80 y principios de los 90. En 1986 se fundó el Parque Tecnológico da Universidade de Brasilia, desde entonces tanto en Brasil como en Argentina y Chile existe un creciente interés puesto de relieve en la organización de la asamblea general de la IASP en 1996 en Brasil. También en Australia el desarrollo de parques científicos o tecnológicos es un fenómeno relativamente reciente. Los principales parques son: el Technology Park Western Australia, el Technology Park de Adelaida, sólo el Brisbane 


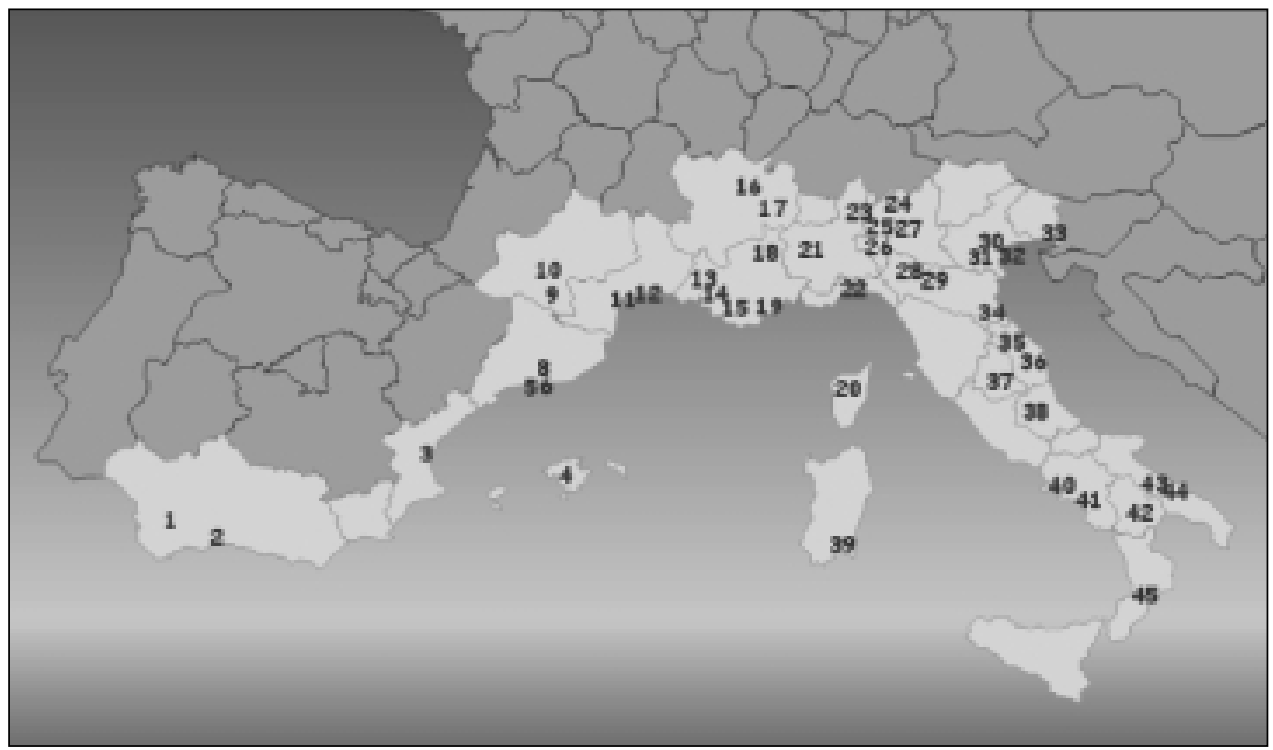

FIGURA 1. Localización de los PCyT en el mediterráneo latino.

\section{ESPAÑA}

1. Sevilla Tecnópolis (Sevilla)

2. Parque Tecnológico de Andalucía (Campanillas -Málaga-)

3. Valencia Parc Tecnològic (Paterna - Valencia—)

4. ParcBit (Palma de Mallorca)

5. Parque Mediterráneo de la Tecnología (Castelldefels -Barcelona-)

6. Parc Científic de Barcelona (Barcelona)

7. Parc Tecnològic de Pedralbes Sud (Barcelona)

8. Parc Tecnològic del Vallès (Cerdanyola del Vallès -Barcelona-)

\section{FRANCIA}

9. Labege Innopole (Labege)

10. Technopole de l'Aglomerátion Toulousaine (Toulouse)

11. Multipole Technologique Régional (Montpellier)

12. Institut De l'Audivisuel et des Télécommunications en Europe (Montpellier)

13. Agroparc, Technopôle Régional d'Avignon (Aviñón)

14. Europole Mediterraneen de l'Arbois (Provenza-Aix)

15. Technopole de Chateau-Gombert

16. Lyon Technopole (Lión)

17. Savoie Technolac (Le Bourget du Lac)

18. Technopole Grenoble Isere (Grenoble)

19. Sophia Antipolis (Varenne)

20. Futura Technopole (Bastia)

\section{ITALIA}

21. Parco Scientifico Tecnologico per l'Ambiente (Turín)

22. Parco Scientifico e Tecnologico di Genova (Génova)

23. Parco Tecnologico di Piemonte (Maggiore)

24. Parco Tecnologico di Balerna (Balerna)

25. Parco Scientifico Tecnologico Sesto San Giovanni (Sesto San Giovanni)

26. Science Park RAF SPA (Milán)

27. Polo Tecnologico Milano Bicocca (Milán)

28. Leonardia - Polo Tecnologico di Piacenza (Piacenza)

29. Polo Tecnologico di Parma (Parma)

30. Parco Scientifico di Padova (Padua)

31. Polo Scientifico e Tecnologico Agrimercato (Padua)

32. Parco Scientifico e Tecnologico di Venezia (Venecia)

33. AREA Science Park Consortium (Trieste)

34. Parco Scientifico-Tecnologico Centuria (Cesena)

35. CESIT - Centro Studi Impresa Territorio (Urbino)

36. Parco Tecnologico delle Marche

37. Parco Tecnologico Agroalimentare Dell'Umbria (Todi)

38. Parco Scientifico e Tecnologico d'Abruzzo (L'Áquila)

39. Consorzio Ventuno (Cagliari)

40. Parco Scientifico e Tecnologico dell'Area Metropolitana di Napoli (Nápoles)

41. Parco Scientifico e Tecnologico di Salerno e delle Area Interne della Campania (Salerno)

42. Parco Scientifico e Tecnologico della Basilicata

43. Parco Scientifico Tecnologico dell'Area Jonico-Salentina (Andria)

44. Parco Scientifico e Tecnologico di Bari (Valenzano)

45. Parco Scientifico e Tecnologico della Calabria (Rende)

FUENTE: Instituto del Mediterráneo Latino y elaboración propia. 
Technology Park, y el Queensland and University of Adelaide Commerce and Research Precint. En Rusia el concepto de parque es muy reciente, concretamente de 1988. La Universidad de Moscú fue una de las primera en tener la iniciativa, seguida de la de San Petersburgo. Inicialmente el Ministerio de Educación planeó la construcción de 50 «tecnoparques», de los que el $90 \%$ nunca pasaron de la fase de diseño debido a restricciones presupuestarias y a cambios en las prioridades. Actualmente, la IASP maneja unos 26 parques que proporcionan espacio y servicios.

De esta variedad de proyectos se desprende que cualquier iniciativa recibe ese nombre maravilloso que va a proporcionar desarrollo tecnológico a las ciudades. Ahora, los parques emanan de las propias colectividades territoriales, universidades y agrupaciones empresariales traduciendo una preocupación por el futuro de la competitividad de las economías en un mundo cambiante y desbocado. La evolución del fenómeno hace que no haya sitio para todos en el mundo de las tecnópolis. De aquellos parques de ciencia se ha pasado a los más jóvenes, que en un intento de diferenciar el territorio o la ciudad buscan un hueco que garantice su viabilidad mediante tres líneas de actuación.

- La especialización mediante parques de servicios médicos, polos especializados en oftalmología, medio ambiente, diseño en automoción, micología o anteproyectos como el centro tecnológico en Castellón de la Plana en torno a los nuevos materiales cerámicos y la bioelectrónica en la isla de Elba.

- La desmaterialización o incubadora sin ladrillos, que busca las sinergias y el efecto multisede entre centros distantes con el fin de crear empresas, generar empleo y atraer inversiones apoyadas en proyectos para el ocio, los servicios avanzados o la comercialización apoyada en la red de redes. La estrategia BIT del Gobierno Balear centrada en el teletrabajo y en la mejora del acceso de los servicios de la administración a los ciudadanos como elemento determinante de la promoción y de las relaciones ciudadano-cliente-proveedor de servicios, es el mejor ejemplo en proyecto.

- Las experiencias piloto de parques virtuales multipolos, como la de Nîmes con más de medio millón de habitantes y el $40 \%$ de la población asalariada en la industria en empresas filiales con sede fuera de la zona. O, el caso de Pisa en la Toscana Occidental (región Objetivo 2) que desde 1997 presta servicios a una población de 1.300.000 Hb.

Ahora, igual que hace décadas se acuñó el término tecnoarchipiélago a Japón, regiones y países enteros como Israel o ciudades como Barcelona se presentan con las características de todo un parque tecnológico. Empresas de alta tecnología como Bull, Matra, Pirelli, Piaggio, Massa Carrara, H. Packard, Intel, Sony, etc., contribuyen a organizar el territorio mediante nuevas iniciativas como son las incubadoras, centros de diseño aplicado, polos de información y formación.

Desde luego, en esta evolución subyace una búsqueda de vínculos necesarios entre tecnología, economía y empleo. Las nuevas iniciativas tienen más vocación que los primeros parques de garantizar la difusión de las tecnologías por el conjunto del tejido empresarial y de la sociedad, pero también es cierto que existe un relativo voluntarismo, a veces, imposible debido a un presente que busca mayores cotas de eficiencia aportando menos recursos. Las últimas experiencias piloto ponen el énfasis en la sociedad del aprendizaje y en aspectos como la educación, información y en los negocios.

En definitiva, los PCyT son unos instrumentos que ponen su énfasis en la industria, en los servicios, y en tareas de I+DT que formen parte del proceso industrial. Hoy, se trata de reconocer una diversidad de actuaciones que fluctúan entre las situaciones locales y aquél carácter único y mítico que estableció el Silicon Valley. Éste tiene su valor en 
la medida que fue un fenómeno más natural, el resto son estrategias y planificaciones. Actualmente, el mismo significado del término PCyT ha ido evolucionando hasta aplicarse a áreas geográficas no limitadas ni constreñidas físicamente, sino a «espacios virtuales» (BOZZO, U., 1995, 356), cuyos límites y formas de organización están en continua evolución. Las últimas iniciativas italianas, francesas y españolas tienden a recobrar una multiplicidad de agentes, recursos y emprendedores con el fin de explotar el cableado de las ciudades.

A pesar de todo este despliegue de parques científico-tecnológicos, conviene aclarar que según la misma Asociación Internacional de Parques Científicos (IASP), en el año 2000 estaban registrados en todo el mundo 2000 iniciativas, de las que 1300 son proyectos de incubadoras y 700, el 35\%, parques científicos y tecnológicos. En 1980 había 39 parques en todo el mundo, en 1990 había 270, y en 1998 se superaban los 500 de los cuales más de un centenar de iniciativas se recogían con diversas denominaciones. En 1999, 120 parques integraban la división europea de la IASP, actualmente se calculan más de 200 parques funcionando en toda Europa. En esta organización que aborda la internacionalización de las pequeñas y medianas empresas y el papel que desempeñan los PCyT en el proceso, se integran una amplia red de 40.000 empresas innovadoras de alta tecnología por todo el mundo (gráfico 1 y cuadro 1$)^{3}$.

\section{Qué son los PCyT: definición y consistencia del fenómeno}

Cincuenta años después de iniciarse el fenómeno existen diversas interpretaciones de lo que se entiende por PCyT. La proliferación de aglomeraciones de actividad con la denominación de alta tecnología durante los años ochenta y noventa ha estado acompañada de la emergencia de una multiplicidad de conceptos y definiciones utilizadas para describir y catalogar las diversas experiencias planificadas con aspectos y características diferentes. En las condiciones vistas anteriormente de evolución hacia nuevas iniciativas para acumular tecnología, definir los PCyT supone acotar una variedad de situaciones. A continuación ofrecemos una serie de definiciones que nos ayudarán a interpretar el concepto de PCyT y sus contornos afines.

\subsection{El concepto de PCyT}

A partir de una configuración que se repite en los proyectos europeos más clásicos hemos buscado un denominador común. En el esquema típico aparecen tres componentes que caracterizan a los parques y que son vectores favorables del desarrollo tecnológico: los centros de investigación públicos, las universidades y las empresas. Estos elementos se mezclan en proporciones diferentes, pueden ser internos o externos al parque, y, dependiendo de cada situación, realizan una o varias funciones según la orientación que los promotores impriman al proyecto.

Así, para estas nuevas áreas se habla de parques de investigación, de incubadoras, tecnópolis, tecnopolos y de parques científico-tecnológicos. Para responder a la pregunta qué

3 Para una referencia hasta mediados de la década de los años noventa véase Ayer, hoy y Mañana de los parques tecnológicos en España, pp. 22-29. Una referencia particular, pero no exclusiva a Gran Bretaña, está trazada en Doreen Massey, Paul Quintas y David Wield, High Tech Fantasies: Technology Parks in Science, Society and Space. Lodres, Routlege, 1992, pág. 9 y en especial el capítulo 5. 
es un parque, cómo se define, qué funciones desempeña, qué características debe reunir estos espacios productivos del siglo XXI, las respuestas las hemos agrupados en cuatro niveles que recogen las definiciones de organismos oficiales, las aportadas por agentes promotores, aquéllas que responden a agentes sociales y económicos, y las aportaciones procedentes del mundo académico e investigador. Con ello se intenta aportar elementos que contribuyan a mejorar la aprehensión del fenómeno.

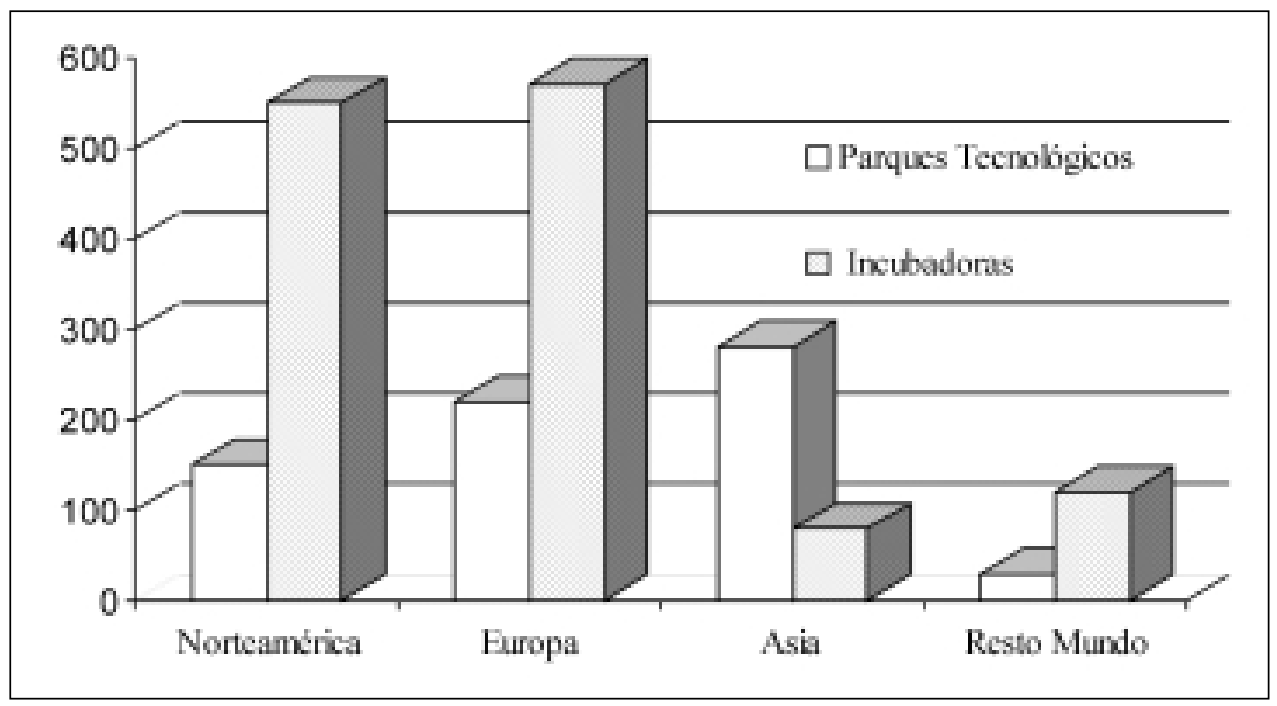

GrÁFICO 1. Parques e Incubadoras en 1999.

FUENTE: elaboración propia.

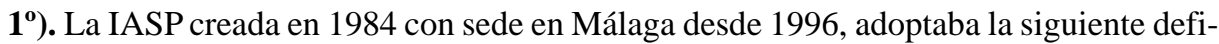
nición ${ }^{4}$. El término Parque Científico se usa para describir una iniciativa basada en la propiedad que:

a) Tiene lazos operativos con una o más universidades, centros de investigación u otras instituciones de educación superior.

b) Está diseñado para alentar la formación y el crecimiento de industrias basadas en el conocimiento y de otras organizaciones que normalmente se encuentran en el emplazamiento.

c) Posee una función directiva que se encuentra comprometida de forma activa con la transferencia de tecnología y técnicas empresariales a organizaciones arrendatarias.

En realidad, si tenemos en cuenta el primer punto, pocos de los PTs españoles entrarían en el esquema. La definición aunque no menciona el término PT lo incluye, y no excluye

4 IASP (1990). General Presentation, IASP Paper, Burdeos. 


\section{Cuadro 1}

LOS PARQUES SEGÚN PAÍSES EN EUROPA, EN 1998

\begin{tabular}{|l|c|c|c|c|c|}
\hline & $\begin{array}{c}\text { Parques Científicos } \\
\text { y de Investigación }\end{array}$ & $\begin{array}{c}\text { Parques } \\
\text { Tecnológicos }\end{array}$ & $\begin{array}{c}\text { Parques } \\
\text { Cientifico-Tenologicos }\end{array}$ & Otros (industriales...) & TOTAL \\
\hline 1 Alemania & 1 & 2 & - & 1 & 4 \\
\hline 2 Inglaterra & 2 & 1 & - & 2 & 5 \\
\hline 3 Bélgica & 1 & 1 & - & 1 & 3 \\
\hline 4 Dinamarca & 2 & - & - & - & 2 \\
\hline 5 España & 1 & 7 & - & - & 8 \\
\hline 6 Estonia & 1 & 1 & - & - & 2 \\
\hline 7 Finlandia & 3 & 5 & - & & 8 \\
\hline 8 Francia & - & 20 & - & 7 & 27 \\
\hline 9 Grecia & 1 & 4 & - & 1 & 6 \\
\hline 10 Hungría & 1 & - & - & 5 & 6 \\
\hline 11 Irlanda & 1 & & - & 1 & 2 \\
\hline 12 Italia & 2 & 3 & & 2 & 7 \\
\hline 13 Lituania & - & - & 1 & - & 1 \\
\hline 14 Noruega & 1 & 2 & & 2 & 5 \\
\hline 15 Países Bajos & 2 & 1 & - & - & 3 \\
\hline 16 Portugal & - & 3 & 2 & - & 5 \\
\hline 17 Rep. Checa & - & 1 & 1 & - & 2 \\
\hline 18 Suecia & 7 & 2 & - & - & 9 \\
\hline 19 Turquía & 1 & & & & 1 \\
\hline TOTAL & 27 & 52 & 4 & 22 & 105 \\
\hline
\end{tabular}

FUENTE: elaboración a partir de datos extraídos a la IASP.

iniciativas con denominaciones tales como Parques de Investigación, Centros de Innovación, Desarrollo de Alta Tecnología, Centro Científico e incluso Tecnópolis como espacios de mayor dimensión, cuando cumplan los criterios esenciales antes establecidos. Posteriormente la misma IASP reconoce la necesidad de mantener lazos formales con una o más universidades (IASP, 1990).

Un PCyT es un lugar dotado de servicios avanzados donde se ubican empresas, que tiene lazos formales u operacionales con una universidad, un centro de investigación o una institución de educación superior. El parque está diseñado para fomentar la creación de industrias basadas en el conocimiento y de empresas de alto valor añadido del sector terciario. Además, tiene un equipo de gestión que anima los fenómenos de la transferencia de tecnología y la mejora de la competitividad de las empresas que allí se ubican (APTE, 1999, 13). 
O sea, que un PCyT es un nuevo espacio creado en gran medida para la difusión y expansión de las nuevas tecnologías. Existe en cualquier lugar donde haya líneas de fibra óptica, cables coaxiales o conexión vía satélite. No especifica ni el tipo de empresas a ubicar ni el tipo de relaciones con centros de investigación, ni las conexiones con el entorno territorial. No plantea el objeto de la innovación y, sin embargo, enfatiza los aspectos organizativos y de gestión en relación con el recinto interior.

La OCDE propone elementos de localización y definición para los parques tecnológicos. La localización responde a todo un conjunto de nuevos factores como son las infraestructuras de comunicaciones, ventajas fiscales, terrenos, mercado laboral y adecuada estructura educativa. La definición que proponen es así: los parques tecnológicos son zonas con superficies variables desde las decenas a varios miles de hectáreas, con las siguientes funciones y características:

a) La función principal es concentrar las industrias de alta tecnología y centros de servicios especializados.

b) Tienen como componente esencial al menos un departamento universitario o instituto tecnológico con el que las empresas concentradas en esa zona pueden comunicarse fácilmente en el plano material e intelectual.

c) Las actividades que realizan empresas, centros e institutos incluyen un importante componente de investigación y desarrollo.

2). Los procesos de innovación han abierto un debate que oscila entre la necesidad de consolidar sistemas de innovación con suficientes recursos para incidir en el entorno productivo y la preocupación por elevar la competitividad y calidad de la industria regional. Así, los parques se incluyen en un conjunto de infraestructuras genéricas de apoyo a la innovación. Su función, además de ofrecer suelo de calidad, es la de operar como nexos tecnológicos entre la ciencia y el entorno productivo.

Frente a esta definición acorde con el fenómeno y los procesos de cambio industrial, se contraponen visiones más restringidas que enfatizan la imagen y los factores técnicos. Un repaso a cierta literatura económica desprende interpretaciones más restringidas que enfatizan la imagen y los factores técnicos. Así, el prerequisito que un parque debe cumplir, aparte de su localización correcta, es ofrecer unas instalaciones de primera calidad que rompan con la imagen tradicional de la región y ofrezcan el elemento de estatus imprescindible para atraer empresas avanzadas (DEL CASTILLO, J.; BARROETA, $M^{a}$. B., 1995, 374). En esta dirección se proponen una serie de factores técnicos para una buena localización y eficiencia de los parques como el área urbana, aeropuerto, universidad.

Estas visiones contemplaron los parques desde la óptica de la oferta de suelo y techo, y se refieren a áreas industriales de nueva planta destinadas a localizar empresas captadas mediante la estrategia de las inversiones. En regiones con escasa tradición industrial y bajo desarrollo tecnológico, la investigación básica o aplicada no es un factor que motive la planificación de parques. En realidad, se refieren a empresas con tecnología avanzada captadas mediante la estrategia de las inversiones directas, y hablan de regiones con «retraso estructural» Objetivo 1 U.E como Castilla y León o Asturias. Esto quiere decir, que en regiones con escasa tradición industrial y bajo desarrollo tecnológico, existe una primera fase necesaria de acumulación de masa crítica empresarial, y que la investigación no es vector que motive la planificación de unos espacios productivos cuya orientación se marca 
hacia la industria y los negocios: los PCyT son proyectos que generan beneficios a nivel de imagen y rendimiento político y económico a los promotores. Los vectores fundamentales no son las sinergias y las redes de cooperación sino el negocio inmobiliario y la comercialización de productos o servicios de mayor valor añadido.

3. En la transición al nuevo paradigma, otras funciones que realizan los parques tecnológicos para articular el desarrollo enfatizan la función inmobiliaria y el mercado de la tecnología. La propia construcción de parques fue un gran negocio en los EE.UU y en España. Entre sus múltiples actividades empresariales, el Consorcio de la Zona Franca de Barcelona asesora con sus buenos oficios una docena de parques en Cataluña, el de Vigo promueve el parque de la ciudad atlántica, el IMADE, Gesturcal o la Agencia de Suelo en Andalucía impulsan los nuevos parques y las incubadoras de media docena de ciudades en cada región.

Desde esta aproximación las principales características que definen un parque tecnológico son las siguientes ${ }^{5}$.

a) Un parque tecnológico es un proyecto inmobiliario que conlleva beneficios en el ámbito de imagen. Es un negocio inmobiliario que busca rendimiento económico a su promotor.

b) Es una comunidad de negocios de tecnología que obtiene beneficios y proporciona valor a cada uno de sus partícipes debido a su red de intereses mutuos. Se identifica con una comunidad internacional aún más amplia de intereses en el negocio de la comercialización de tecnología.

c) Actúa como un imán para las inversiones fuertes en tecnología. Atrae a los negocios que se dedican a aplicar una tecnología innovadora. Es un puente hacia el campo comercial de la investigación aspecto de importancia para los intereses comerciales

d) Un parque es una incubadora de actividades basadas en tecnología que permite a los investigadores iniciar un negocio utilizando sus ideas innovadoras sin tener que abandonar necesariamente su trabajo académico.

4. Los parques han sido y son estudiados teniendo en cuenta los primeros trabajos empíricos realizados por el grupo de investigación GREMI sobre los medios innovadores (MAILLAT, D.; QUEVIT, M., 1993), y los análisis que Castells y Benko realizaron en las concentraciones industriales de «alta tecnología» existentes en el mundo.

A partir de estos estudios, las ventajas territoriales capaces de articular el desarrollo regional se han buscado en áreas urbanas y metropolitanas con capacidad de innovación tecnológica. Con independencia de las funciones que se realicen, la característica esencial de estas nuevas áreas productivas es el tipo de producto fabricado, normalmente relacionado con las nuevas tecnologías, el tipo de empleo, las actividades, la facturación y los gastos de las empresas.

Castells, para definir los requisitos que deben cumplir, se refiere a «factores críticos»o decisivos que juegan los gobiernos para el desarrollo de regiones con un escaso nivel de industrialización previa. Y, Benko plantea una batería de nuevos factores de localización

5 Esta visión de negocio inmobiliario en auge entre los años 1986-1997 tuvo sus representantes entre expertos, promotores, constructores, etc. Véase Hodgson, B., (1994), «Factores de éxito en los Parques Científicos». En Scheifler Mª.A. (coord.). Los Parques Científicos. Principales experiencias internacionales. Edit. Civitas, Madrid, págs. 43-63. 
para diferenciarlos de otros espacios. El primero, enfatiza la fuerte presencia de los gobiernos públicos, y el segundo se preocupa más por buscar factores explicativos de la industria de alta tecnología dentro del cambio industrial. El resultado de esta combinación es que los parques se definen por la presencia de instituciones dedicadas a la investigación y a la formación, los incentivos fiscales y financieros tanto para la atracción y localización de las empresas como para las actividades de I+D, la disponibilidad de suelo industrial urbanizado con infraestructuras suficientes para el desarrollo de nuevos procesos industriales (aguas, red eléctrica, telemática), un mercado de trabajo local amplio y diversificado con ingenieros y técnicos de calidad, un buen sistema de transportes y comunicaciones rápido y eficaz que incluya proximidad a un aeropuerto de primer nivel, por el atractivo y la calidad del entorno, la ubicación geográfica y la imagen y la flexibilidad de las instituciones.

Desde 1995 el término PT y posteriormente el de PCyT se utilizan indistintamente como denominación genérica de los cinco tipos de MITs definidos por Castells. Un MIT («Medios de Innovación Tecnológica») es «un conjunto específico de relaciones de producción y gestión, basado en una organización social que comparte esencialmente una cultura profesional y unos objetivos instrumentales dirigidos a la generación de nuevo conocimiento, de nuevos procesos y de nuevos productos». Una característica fundamental de estos espacios para la innovación es su capacidad de elevar el valor final de la producción mediante la combinación territorial de sus elementos. De modo similar al milieu, el resultado final de un MIT, también es superior a la suma de sus elementos separados. Por lo tanto, y hasta aquí, los PCyT son zonas industriales especializadas en la producción, adaptación y difusión de nuevas tecnologías. La planificación corresponde a diferentes administraciones públicas, y están destinadas a concentrar actividades avanzadas y empresas que operan en «sectores de alta tecnología» (BENKO, G., 1991, 12; CASTELLS, M, 1994, 129).

Hoy día los investigadores, la literatura especializada y determinadas instituciones de investigación se refieren a un área regional o local en la que se concentran actividades caracterizadas por un notable contenido científico y tecnológico. Para MÉNDEZ-CARAVACA (1993), los PTs son «actuaciones promovidas con el apoyo de organismos autonómicos y locales, que buscan el asentamiento de industrias ligadas a la alta tecnología, junto a centros de investigación, diseño e innovación, y centros de servicios integrados que faciliten una efectiva sinergia del sistema ciencia-tecnología-industria» (MÉNDEZ, R.-CARAVACA, I., 1993, 155).

Más precisamente, el mismo término también se emplea para definir un espacio innovador específico, principalmente constituido por las instituciones universitarias y otros centros de investigación fundamental. Su objetivo es atraer empresas, principalmente de pequeña y media dimensión, cuya producción es dependiente del saber hacer y de las relaciones continuas de intercambio con los agentes científicos del área.

Desde esta óptica, a los PCyT se les atribuye un significado, un propósito y unos objetivos diferentes a otros espacios industriales coetáneos. Por tanto, los PCyT se planifican no sólo como espacios para ubicar empresas, sino que en general se hacen inteligibles en la interacción del conocimiento mediante agentes que incluyen acciones innovadoras en aspectos económicos, sociales y territoriales. Esta interpretación, por la que dichos entornos están habitados por conocimiento que a su vez debería llamar a más conocimiento, está descrita y analizada por una amplia literatura generada en el seno de las ciencias económicas y de la nueva geografía económica e industrial, con referencias a varias áreas geográficas (BENKO-LIPIETZ, 1996; MÉNDEZ, R. 1997). Además, si remarcamos la función de 
nexo entre la ciencia y la industria, los parques tecnológicos deberían generar y facilitar sinergias efectivas entre la ciencia, la tecnología y la industria, y se diferencian de los parques científicos en que éstos están promovidos por universidades o centros de investigación (MÉNDEZ, R.; CARAVACA, I. 1993, 1996).

Incluso a pesar de las dinámicas de aprendizaje positivas que podemos observar en los nuevos parques, en los estudios actuales sobre las relaciones entre innovación y territorio, la innovación en los parques tecnológico-científicos podría gestarse sin medio de innovación quedando reducida a recintos cuasiestancos (MAILLAT, D., 1995; MÉNDEZ R.; ALONSO, J.L. y otros 1998).

En definitiva, unos conceden importancia al potencial investigador, otros enfatizan los procesos de innovación tecnológica en un grupo más específico de sectores nuevos y agentes entre los que se encuentran las empresas más avanzadas. La misma IASP concede importancia al término parque tecnológico o científico no sólo como infraestructuras físicas. Y, los promotores-empresarios enfatizan los beneficios asociados a la imagen, comercialización y localización. El hilo conductor de todas estas argumentaciones es la tecnología como motor de crecimiento en interacción con múltiples agentes. Entre unos y otros se planifican y desarrollan los parques. A esto se añade el diseño de políticas destinadas a crear tejido empresarial mediante nuevas infraestructuras con denominaciones que sólo a veces tienen los mismos objetivos.

\subsection{Tipología, características y funciones}

Durante los años ochenta y noventa la proliferación de aglomeraciones con la denominación de alta tecnología, tecnología avanzada, centros y empresas innovadoras, ha estado acompañada de la emergencia de una multiplicidad de denominaciones utilizadas para describir y catalogar las diversas experiencias, que se han planificado con aspectos y características diferentes. Pero en las circunstancias actuales del conocimiento entre las

\begin{tabular}{|c|c|c|c|c|c|}
\hline \multicolumn{6}{|c|}{$\begin{array}{l}\text { Parque Tecnológico; Parque Cientifico; Parque TyC; Parque de Investigación; } \\
\text { Tecnópolis; Medio de Innovación; Otras denominaciones. }\end{array}$} \\
\hline \multicolumn{2}{|c|}{$\begin{array}{l}\text { 1. El parque es más que } \\
\text { un conjunto de edificios. } \\
\text { Está legalmente } \\
\text { constituido como } \\
\text { instrumento de desarrollo } \\
\text { económico y social. }\end{array}$} & \multicolumn{2}{|c|}{$\begin{array}{l}\text { 2. Las actividades no son } \\
\text { sólo negocios. El parque y } \\
\text { sus empresas sirven para } \\
\text { crear conocimiento y elevar } \\
\text { el contenido tecnológico de } \\
\text { los factores productivos }\end{array}$} & \multicolumn{2}{|c|}{$\begin{array}{l}\text { 3. Tiene relaciones } \\
\text { formales operativas con } \\
\text { alguna universidad } \\
\text { cercana para transferir } \\
\text { conocimiento y tocnologia } \\
\text { (I+D) entre empresas, } \\
\text { Dptosy tejido industrial }\end{array}$} \\
\hline NO & \multicolumn{2}{|c|}{ SI } & \multicolumn{2}{|c|}{ NO } & SI \\
\hline $\begin{array}{l}\text { Vivero, } \\
\text { Incubadora, } \\
\text { CEI }\end{array}$ & \multicolumn{2}{|c|}{ Parque Tecnológico } & \multicolumn{2}{|c|}{$\begin{array}{l}\text { Parque Industrial, } \\
\text { Parque Empresarial }\end{array}$} & $\begin{array}{c}\text { Parque } \\
\text { Tecnologico } \\
\text { y Cientifico }\end{array}$ \\
\hline
\end{tabular}

Fucnle: Elaboración propia.

FIGURA 2. Los parques según su contribución al desarrollo tecnológico e industrial. 
definiciones acuñadas para definir estos proyectos urbanos y la evolución observada existen contradicciones que oscilan entre aquéllas más específicas y otras más genéricas. Uno de los primeros documentos oficiales publicado por la U.E en 1990 amuebló una clasificación de las diversas tipologías de concentración de actividad high-tech. En paralelo y a menudo como especificación posterior de estas definiciones oficiales, los grupos inmobiliarios, las agencias de suelo e incluso gestores de la tecnología han extendido otras denominaciones para identificar las áreas que acogen actividades y empresas con mayor o menor contenido tecnológico.

La figura 2 aporta unos criterios mínimos para diferenciar los parques en función de que existan o no vinculaciones reales con centros de investigación y compromisos de desarrollo tecnológico y económico con el tejido donde se localizan las diferentes iniciativas.

Aunque la terminología que actualmente viene utilizándose con más frecuencia es la de parque científico y tecnológico, la diversa tipología de concentración de actividad innovadora y de alta tecnología queda como sigue.

1. El parque científico es una iniciativa de base territorial situada en la proximidad de institutos y centros politécnicos superiores o centros de investigación avanzada. Está destinado a estimular la creación y el crecimiento económico basado en el nuevo conocimiento promoviendo activamente la transferencia de tecnología desde las instituciones académicas y de investigación al tejido y a la organización incluida en el ámbito o extensión del parque. La función principal del parque se constituye por las actividades de investigación, desarrollo y planeamiento, concepción de nuevos productos-servicios y el desarrollo de los pasos finales a la fase de comercialización. El trabajo de I+D efectuado por las empresas en el ámbito del parque, a menudo es limitado a la elaboración de prototipos, encauzar la fabricación hacia otros lugares o localizaciones, aunque en algunos casos las empresas comprendidas en los parques científicos manejan excepcionalmente la producción de equipos o sistemas de alta tecnología.

2. Un parque de investigación se sitúa normalmente en el entorno de una universidad o de una institución académica o de investigación. Las actividades desarrolladas son principalmente de búsqueda e investigación en lugar de desarrollo, por lo que el elemento característico está constituido por la investigación en actividades de vanguardia científica y tecnológica absoluta.

3. Un parque tecnológico comprende empresas empeñadas en la aplicación comercial de alta tecnología, con actividades comprendidas entre la I+DT, producción, venta, asistencia y mantenimiento. El parque tecnológico se distingue de un parque científico o de investigación por la mayor importancia de la actividad de producción, mientras que la participación de instituciones académicas no reviste importancia esencial.

4. Un centro de innovación es una estructura destinada a satisfacer la exigencia y necesidades de empresas generalmente nuevas, empeñadas en el desarrollo y en la comercialización de nuevos productos y procedimientos tecnológicos, con relativo alto riesgo de mercado, y la necesidad no sólo de servicios de ayuda y consulta sino también de verdaderas instituciones financieras regionales. El propósito de los centros de innovación es promover la creación de empresas de alta tecnología, sobre todo aquéllas de pequeño y mediana dimensión. Ellos son también incluidos en proyectos más amplios como los parques científicos o tecnológicos de los que se convierten en parte integrante. 
5. La incubadora comercial es un centro en cuyo seno se concentra, en un espacio limitado, empresas de nueva creación. El objetivo es aumentar la posibilidad de desarrollo y la tasa de supervivencia de tales empresas, poniendo a su disposición edificios de carácter modular con servicios de asistencia comunes.

6. El parque empresarial o comercial provee un ambiente de alta calidad, a una vasta gama de actividades como la producción más o menos limpia, ensamblaje, venta, exposición y otras actividades administrativas. Algunos parques tecnológicos y científicos que no han tenido éxito en atraer una verdadera y propia clientela científica han pasado a esta categoría.

7. También encontrarnos el término «distrito tecnológico», polo tecnológico, «polo o parque científico-tecnológico», e incluso «tecnópolis». La tecnópolis es considerada como una entidad limitada espacialmente, es decir, un tipo de ciudad que promueve en masa las actividades de alta tecnología. Ésta posee una estructura y recursos propios, y al mismo tiempo un estado de espíritu que es la característica específica. En las interpretaciones más sugestivas, la tecnópolis no es únicamente un área de actividad para la materia gris y la producción, por el contrario es una verdadera ciudad que ofrece todas las funciones y servicios urbanos típicos como la residencia, educación, recreo, ocio y asistencial.

Hoy día el término parque científico y/o tecnológico es el más usado por los investigadores y por la literatura especializada. Su morfología se acerca a un conjunto de localizaciones abiertas en las que se ofrecen factores fundamentales para el desarrollo tecnológico. En tales espacios las funciones de los PCyT crean y traducen una atmósfera adecuada capaz de promocionar el desarrollo tecnológico, económico y social creando tejido nuevo. Los PCyT deben identificarse con un emplazamiento o lugar físico pero cada vez más con agentes reales que generan las estructuras e infraestructuras adecuadas en donde se localizan redes de servicios que ayudan a las empresas durante las fases de inicio, despegue, consolidación y madurez.

La existencia, la creación y la concentración en determinado lugar o espacio, de actividad de investigación y sus afines es un fenómeno de un lado fuertemente condicionado a las características geográficas del entorno, y por otro lado es particularmente incisivo para modificar estas características y generar peculiares problemas a los que hacer frente. En particular, se viene resaltando el rol y los problemas territoriales de algunas áreas de producción avanzada más o menos vinculadas al ambiente universitario. Existen ejemplos más evidentes del significado territorial de la concentración espontánea o programada en un área rellena de centros universitarios, actividad de investigación pública y privada o producción tecnológicamente sofisticada, como en los Estado Unidos, Países de Europa Occidental y Japón. En tales casos, términos nuevos como ciudad de las ciencias, parque científico y tecnópolis son, en el mundo desarrollado, conceptos referidos e identificativos del nuevo orden territorial de la organización productiva, que siempre resulta condicionada a la innovación tecnológica y a las inversiones en investigación. Nuevo orden y nuevos espacios sostenidos como una versión moderna de los polos de desarrollo perrouxianos, sólo que ahora la localización de la actividad aparece a lo largo y a lo ancho de una geografía económica más delicada si cabe.

Sobre esta nueva centralidad en términos de Christaller o motriz, si se prefiere el lenguaje de Perroux, se siembra y se impone en el mundo occidental la jerarquía urbana del siglo XXI ligada a la producción de alta tecnología, a la creación de saber científico y tec- 
nológico, a los servicios sofisticados, a las relaciones internacionales, al trabajo de imaginación y a las funciones más inmateriales. Visto así, la proximidad física entre centros de investigación y áreas de producción es una de las principales condiciones para la difusión de las innovaciones.

\section{Parques e innovación: nuevos tiempos, nuevos retos}

Cuando se abordan los proyectos de parques en curso observamos que los promotores hacen especial énfasis en la función de innovación que imprimen estos nuevos espacios. Conviene realizar algunas matizaciones finales extraídas tras quince años de geografía de la innovación.

En primer lugar, en los espacios industriales convencionales (zonas de concentración industrial, polígonos industriales), la aparición de un valor añadido surgía de las economías de escala que actuaban básicamente sobre los costes. En estos espacios de carácter generalista la actividad industrial medida desde el punto de vista de establecimientos, empleo, volumen de producción, facturación, etc., ha sido una finalidad justificada por sí misma y, por tanto, lo prioritario, con independencia de la naturaleza de la producción. Ahora, con los parques tecnológicos y científicos como medios de innovación, lo importante es buscar valor añadido o externalidades positivas bajo la forma de relaciones capaces de generar sinergia.

Hay medio de innovación cuando la localización de actividades de I+DT tiene un efecto multiplicativo y no sólo aditivo. Es decir, cuando el hecho de situarse en un determinado espacio y beneficiarse de una serie de mecanismos de interacción genera efectos de sinergia, esto es, procesos de innovación que se refuerzan los unos a los otros y que incrementan considerablemente el potencial individual de cada una de las unidades participantes en el medio. Esto es determinante para el éxito de los espacios tecnológicos. Si no hay efectos de sinergia no hay medio de innovación, porque «la innovación es en parte una aptitud social. Conseguir un ambiente propicio y sensible a la innovación en sus diferentes facetas es el mejor caldo de cultivo para que el esfuerzo innovador tenga éxito, se retroalimente así mismo y sea asumido como propio por un sector lo más amplio posible de la sociedad» (RICO, A., 1988, 142-152).

En segundo lugar, de las aportaciones del GREMI, de la teoría de los medios de innovación de Castells-Hall, de los estudios de Benko, y también de la definición propuesta por la IASP, se deduce que la constitución de medios de innovación tecnológica (PCyT) es un factor de producción que beneficia al conjunto de la economía regional, más allá de sus miembros individuales.

Sin embargo, un aspecto que será de suma importancia en las primeras fases de los PCyT es precisamente su viabilidad económica. Un parque es mucho más que una operación inmobiliaria de suelo y edificios. No debe tener por finalidad exclusiva recuperar unas inversiones realizadas con anterioridad o rentabilizar con criterios de mercado el suelo urbano, las redes telemáticas interiores y las aplicaciones tecnológicas que vayan surgiendo. Lo que debe predominar, debe ser la búsqueda de la aparición de relaciones de sinergia entre los agentes partícipes así como la transferencia de los resultados al conjunto del tejido social.

Por último, la empresa moderna opera innovando, comprando información, transfiriendo y ejerciendo el control de la misma. A través de esta función, se aprecia cómo los agentes configuran un modelo de innovación metropolitana en concordancia con los rasgos mercantiles de los grupos promotores e inmobiliarios y de las empresas que valorizan la tecnología. Esta función sobrepasa los aspectos morfológicos, urbanísticos y de organiza- 
ción de los parques mediante un modelo en torno al mercado, los servicios-productos y los sistemas de apoyo. Detrás de todas estas características últimas subyace una definición económica y utilitaria de la tecnología que gira en torno al estímulo del provecho de las infraestructuras y de la propia ciencia.

Hacer ciencia e innovar en garajes no será propio del siglo XXI. La función de los PCyT con su capital humano y sus laboratorios destinados a la investigación intensifica un nuevo estadio que podemos denominar industrialización de innovación. Esto presupone una masa crítica de empresas, agentes e individuos trabajando en sectores y actividades determinadas y en un clima de optimismo temporal o cíclico, en el cual las ideas y sus aplicaciones afluyen y se suceden con rapidez, produciéndose una reacción en cadena que no sólo es necesario valorizar sino que además es necesario volver a innovar.

\section{Bibliografía}

ABE, Sh. (1998): «Regional innovation system in Japan: the case of Tohoku». En BraczykCooke y otros (1999) Regional Innovation System. pp. 289-319 UCL Press, London.

ADEN, W. (1994): «Centros Tecnológicos y Parques Tecnológicos, dos elementos de una misma política regional. El caso de Dortmund (Alemania)». SCHEIFLER, $\mathbf{M}^{\mathrm{a}}$. A. (Coord.): Los parques científicos. Principales experiencias internacionales, pp. 235240, Ed. Civitas, Madrid.

ALLESCH, J. (1995): «El papel de los centros de innovación y transferencia tecnológica», Quaderns de Tecnología, pp. 66-78, ICT, Barcelona.

APTE (1999): Red de Parques Científicos y Tecnológicos Miembros. Apte, Málaga.

BENKO, G. (1991). Géographie des technopôles. Ed. Masson, París.

BOZZO, U. (1995): «Los parques tecnológicos: Un modelo de empresa». Políticas Regionales Industriales, Innovación y Parques Tecnológicos, pp. 355-369. Universidad de Valladolid. Valladolid.

CASTELLS, M.; HALL, P. (1994): Technopolos of the world. The making of twenty-firstcentury industrial complexes. Routledge, London and New York.

DATAR, (1988), Technopôles, DATAR, París.

DEL CASTILLO, J.; DÍEZ, Ma ${ }^{\text {.A.; }}$ BARROETA, B. (1995): «Technology parks and university-business relations in Spain». Industry \& Higher Education, pp. 340-348, Brighton, Reino Unido.

EDGINGTON, D. (1999): «Firms, Governments and Innovation in the Chuyo Region of Japan. Urban Studies, vol. 36, n 2, pp. 305-339.

FUYITA, M.; ISHII, R., (1999): «Gnlobal Location Behavior and Organizational Dynamics of Japanese Electronics Firms and Their Impact on Regional Economies». En BraczykCooke y otros (1999) Regional Innovation System. pp. 343-384, UCL Press, London.

GAMA, R. (1997): «Indústrias inovadoras, Território e Desenvolvimento Regional -O Instituto Pedro Nunes (Coimbra)», II Colóquio Internacional Cidades Médias e Desenvolvimento Territorial, pp. 23-40, Centro de Estudos Geográficos, Universidade de Coimbra.

GIFU (1998): Softopia Japan. Company Profile. Planning Department, Gifu Prefecture Government.

IASP (1996): The Economics of Science Parks. Universidad de Brasilia, Brasil.

IASP (1998): Delivering Innovation. Key lessons fron the World-Wide Network of Science and Technology Parks. PT de Andalucía, Málaga. 
IASP (1998): European Survey «Science \& Technology Parks: the tenants point of view, PT de Malaga, Málaga.

ITOOH, T. y otros (1996): Technology in the 21 st Century. Future Reading for an Information-Oriented Society. IOS Press, Tokio, Oxford and Amsterdam.

MAILLAT, D.; QUEVIT, M.; SENN, L. (Edis.) (1993): Rèseaux d'innovation et milieux innovateurs: un pari pour le dèveloppementent régional, GREMI-EDES, Neuchâtel.

MAILLAT, D. (1995): «Milieux innovateurs et dynamique territoriale». En Rallet, A.; Torre, A. (dirs.) Economie industrille et econommie spatiale. pp. 211-231, Económica, París.

MALEZIEUX, J. (1993). «Hautes technologies —nouveaux espaces d'activités- développement local et régional- apparences et réalités. Réflexions sur les aménagements francais». Actas del V Colloque Internacional: Novas Tecnologías e Desenvolvimento Regional. pp. 157-167, U.G.I., Universidad de Coimbra.

MÉNDEZ, R.; CARAVACA, I. (1993): Procesos de reestructuración industrial en las aglomeraciones metropolitanas españolas, MOPT, Madrid.

MÉNDEZ, R.; CARAVACA, I. (1995): «Efectos territoriales de la reestructuración productiva en España». Ciudad y Territorio, pp. 715-744. MOPTMA, Madrid.

MÉNDEZ, R.; CARAVACA, I. (1996): Organización Industrial y Territorio. Ed. Síntesis, Madrid.

MÉNDEZ R.; ALONSO J. y OTROS (1998): «Los medios innovadores: perspectivas teóricas y posibilidades de aplicación a la Península Ibérica». Documento de Trabajo para el Seminario Innovación industrial y desarrollo local en la Península Ibérica. pp. 5-27, Universidad de Salamanca.

ONDÁTEGUI, J. (1997): «Los parques tecnológicos en España: una síntesis geográfica». Boletín de la AGE, nº 24, pp. 73-89.

ONDÁTEGUI, J. (1997): «Nuevos espacios productivos: tecnología, industria y servicios en la región de Madrid». Ciudad y Territorio, $\mathrm{n}^{\circ}$ 112, pp. 357-378, Ministerio de Fomento, Madrid.

ONDÁTEGUI J. (1999): Redes de Innovación y Desarrollo Regional en el Noroeste Peninsular. Revista de Estudios Regionales, $\mathrm{n}^{\circ}$ 55, pp. 77-109, Universidades de Andalucía, Málaga. ONDÁTEGUI J. (1999): «Innovación y desarrollo regional en el Vallés Occidental». ERÍA, Departamento de Geografía, Universidad de Oviedo, Oviedo.

ONDÁTEGUI, J. (2000): Evolución y situación actual de los parques científios y tecnológicos en España. Cotec, Madrid.

PERULLI, P. (1995): Atlas metropolitano: El cambio social en las grandes ciudades. Ed. Alianza, Madrid.

RICO, A., (1992): «Política Industrial, Servicios y Regiones», Economía Industrial, pp. 123-135. MINER, Madrid.

SAXENIAN, A. (1990): «Regional Network and the Resurgence of Silicon Valley», California Management Review, $\mathrm{n}^{\circ}$ 33, pp. 89-112. Berkeley, California.

SAXENIAN, A. (1991): «The origins an Dinamics of Production Networks in Silicon Valley», Research Policy, n $^{\circ}$ 20, pp. 423-437.

SAXENIAN, A. (1993): Regional networks: industrial adaptation in Silicon Valley and route 128. University College, London Press, London.

SAXENIAN, A. (1994): Regional Advantage, Harvard University Press, Cambridge.

VEIGA, J. (1991): «Parques e Polos de Ciéncia e Tecnología: O Desenvolvimento do Polo Tecnológico de Lisboa/Lumiar». Ingenium Revista da Ordem dos Engenheiros, pp. 28-36, Lisboa. 